\title{
O uso da gestão do conhecimento no processo de avaliação de cursos de graduação
}

Dáila Elisa Dorfey

Pós-Graduação em MBA em Gestão Empresarial e Bacharelado em Secretariado Executivo pela Universidade de Santa Cruz do Sul (UNISC) Analista Administrativa do Núcleo de Avaliação Institucional da Graduação - NAIG/UNISC

Rejane Frozza

Professora Doutora do Departamento de Informática e do Programa de Pós-Graduação em Sistemas e Processos Industriais, Mestrado, da Universidade de Santa Cruz do Sul (UNISC). Doutorado em Ciência da Computação pela Universidade Federal do Rio Grande do Sul (UFRGS)

http://dx.doi.org/10.1590/1981-5344/1902

A proposta deste trabalho é desenvolver e implantar um espaço virtual, baseado nas informações levantadas no diagnóstico realizado no setor de avaliação de uma universidade, que atenda às necessidades dos seus membros, no sentido de assegurar a uniformidade e a troca das informações sobre as atividades desenvolvidas. Neste sentido, optou-se pelo desenvolvimento de uma wiki, que permite que os membros do setor insiram informações ou modifiquem os textos já publicados, contribuindo, desta forma, com a contrução de um conhecimento coletivamente. Pode-se destacar que a facilidade no acesso e registro de informações traz como resultado imediato a retenção do conhecimento, auxiliando na melhoria das atividades desempenhadas no setor.

Palavras-chave: Gestão do conhecimento; Processo de avaliação; Ferramenta colaborativa.

Recebido em 17.10.2013 Aceito em 23.01.2015 


\section{Introdução}

Nas organizações, aplica-se e constrói-se constantemente um conhecimento que precisa ser preservado e disseminado. Na constante busca de aliar produtividade à qualidade torna-se essencial que o conhecimento existente nas organizações, proveniente da experiência de mercado e das pessoas que fazem ou fizeram parte do seu grupo, seja gerado, mantido, aumentado e disseminado (DORFEY, 2009).

O tema deste artigo refere-se à Gestão do Conhecimento como apoio ao processo de Avaliação/Regulação dos Cursos de Graduação da Universidade de Santa Cruz do Sul (UNISC).

O problema de pesquisa foi identificado a partir de um diagnóstico realizado no Núcleo de Avaliação Institucional da Graduação da UNISC NAIG. Vasconcellos (2006, p. 188) define o diagnóstico como "[...] localização das necessidades da instituição, a partir da análise da realidade e/ou do confronto com um parâmetro aceito como válido".

O diagnóstico realizado aponta para a necessidade de um espaço para estudos e reflexões sobre as atividades do setor. Tal espaço com o objetivo de atualizar e assegurar a uniformidade das informações sobre as atividades desenvolvidas no setor, bem como, o repasse eficaz de informações/decisões provindas de reuniões.

Desta forma, o problema de pesquisa pode ser caracterizado como: "Um espaço compartilhado de informações/experiências das pessoas envolvidas no processo de avaliação, pode trazer melhorias para as atividades desempenhadas pelo setor?".

As atividades quanto à Avaliação/Regulação desenvolvidas pelo NAIG envolvem todo aparato legal do Ministério da Educação para a Educação Superior no país, além das políticas institucionais. O que, em termos de regulação dos cursos de graduação, para os atos de autorização, reconhecimento e renovação de reconhecimento são cadastrados os processos que seguem os prazos estipulados pelo Ministério da Educação (MEC) para preenchimento de formulários eletrônicos, bem como, visita de avaliação in loco.

Como espaço de estudos e reflexões, optou-se pelo desenvolvimento de um espaço virtual, devido à facilidade de interação e eficiência, permitindo o compartilhamento do conhecimento e de informações. Desta forma, estando disponível e acessível a qualquer momento para todos os membros envolvidos nas atividades, pois nem sempre é possível realizar reuniões e discussões pessoalmente.

Pretende-se com a implantação do espaço virtual no setor, que este possa vir a contribuir para uma maior disseminação das informações entre os membros do setor (experiências e lições aprendidas em avaliações anteriores), agregar qualidade ao desempenho profissional e, ao mesmo tempo, contribuir como subsídio para reflexões sobre avaliação. O que contribuirá significativamente para a otimização na organização e na realização das atividades dentro dos prazos estabelecidos pelo MEC.

Assim, o objetivo principal deste trabalho é desenvolver e implantar um espaço virtual, baseado nas informações levantadas no diagnóstico 
realizado no próprio setor, que atenda às necessidades dos seus membros, no sentido de assegurar a uniformidade e a troca das informações sobre as atividades desenvolvidas. O local de implantação do espaço virtual é no Núcleo de Avaliação Institucional da Graduação da Universidade de Santa Cruz do Sul (UNISC).

Os objetivos específicos estabelecidos para o trabalho são: Pesquisar sobre a área de gestão do conhecimento e sua aplicabilidade na troca de informações nas atividades desenvolvidas no Núcleo de Avaliação Institucional da Graduação da UNISC; pesquisar sobre a Avaliação/Regulação dos cursos de graduação e seus benefícios na maneira de captar e disponibilizar o conhecimento; desenvolver o espaço virtual com a técnica escolhida, neste caso, a wiki; implantar e validar o espaço virtual no Núcleo de Avaliação Institucional da Graduação da Universidade de Santa Cruz do Sul (UNISC).

O texto está organizado da seguinte forma: a seção 2 aborda os temas referentes à fundamentação teórica e os trabalhos relacionados. A seção 3 aborda os procedimentos metodológicos. A seção 4 apresenta a análise do diagnóstico. A seção 5 apresenta 0 desenvolvimento da ferramenta (wiki). E a seção 6 apresenta as conclusões.

\section{Fundamentação teórica} trabalho.

Esta seção abordará os temas da fundamentação teórica do

\subsection{Gestão do conhecimento}

As organizações estão buscando alguma vantagem sustentável que as diferencie das outras em seu ambiente de negócio, utilizando para isso seu conhecimento, que é considerado um dos mais importantes recursos de uma organização (DORFEY, 2009).

Assim, a gestão do conhecimento é definida por Beal (2004) e Davenport; Prusak (1998), como o conjunto de ações sistemáticas e disciplinadas que uma organização pode adotar para obter o maior retorno possível do conhecimento disponível.

Na perspectiva apresentada por Sterndale-Bennett (2001) e Accorsi (2011), fazem parte da gestão do conhecimento a criação, a evolução, a troca e a aplicação de novas ideias para produtos e serviços comercializáveis destinados ao sucesso da organização, à vitalidade da economia de uma nação e ao avanço da sociedade. Em conformidade com estas ideias, segundo Quinn et al. (2002) e Accorsi (2011), o principal desafio da gestão do conhecimento consiste em estimular a criação de novos conhecimentos, isto é, aprendizagem e sua gestão.

Pode-se dizer que a gestão do conhecimento tem como objetivo maximizar o valor do conhecimento de uma organização, pública ou privada, facilitando aos colaboradores externalizar os seus conhecimentos e a serem inovadores e flexíveis perante às constantes mudanças de cenários. Essa mutabilidade impulsiona as organizações a valorizar e 
utilizar dados, informação e conhecimento, independentemente de seus conceitos, para atingirem a eficiência e eficácia nos seus processos e em sua tomada de decisão. A gestão do conhecimento, através de suas práticas, busca proporcionar um melhor aproveitamento do Capital Intelectual e das competências dos seus colaboradores de forma sistemática. Deste modo, procura auxiliar e dinamizar os processos criativos e os de decisão (ACCORSI; COSTA, 2013).

O conhecimento pode ser classificado como explícito e tácito. O conhecimento explícito pode ser resumido como sendo toda a carga de informação digerida e analisada por um indivíduo que, por meio de técnicas estruturadas, permite a sua disseminação, ou seja, é aquele que pode ser transformado em documento, roteiro e treinamento, por exemplo (DORFEY, 2009).

O conhecimento tácito é o resultado de experiências vividas pelo indivíduo como elemento observador de seu mundo em diversos cenários, ou seja, é aquele difícil de registrar, documentar ou ensinar a outras pessoas, é de difícil transmissão ou descrição, já que está implícito na mente e nas ações das pessoas (DORFEY, 2009).

A conversão do conhecimento tácito para explícito é uma tarefa complexa Argote e Ingram (2000) e Gubbins et al. (2012), porque, segundo Gubbins et al. (2012), os indivíduos são seus repositórios fundamentais, e são agentes ativos na sua utilização, ou seja, vai depender da capacidade de um indivíduo e da sua disposição em se envolver no processo de transferência de conhecimento.

A gestão do conhecimento deve estar apoiada em uma cultura organizacional que vislumbre o conhecimento como um valor e que perceba os indivíduos como sua fonte principal. Os conceitos e processos que compõem esta teoria devem resultar em novos conhecimentos, soluções, inovações e também na evolução da aprendizagem organizacional (ACCORSI, 2011).

O aprendizado relaciona-se com a forma como interagimos no mundo e com as capacidades que desenvolvemos a partir de nossas interações. O que difere é a profundidade da percepção, e, como consequência, a fonte a partir da qual atuamos (JAWORSKI et al., 2007).

Desta forma, a gestão do conhecimento pode proporcionar, através de seus conceitos e processos, uma plataforma para que todos os colaboradores organizacionais interajam e percebam na prática os benefícios de aprender por meio do conhecimento coletivo (ACCORSI, 2011).

\subsection{Avaliação e regulação dos cursos de graduação}

A avaliação é um tema de grande relevância para a Educação Superior. Segundo Pfeifer (2012) subscrita na órbita das Políticas de Educação, se efetiva como ferramenta estratégica da administração pública, tanto no processo de fiscalização quanto de promoção da Educação Superior no país. 
Conforme Scheffer (2007) as diferentes experiências de avaliação da educação superior no país, nas últimas três décadas, seguem modelos de avaliação combinados de outros países.

Do conjunto dessas experiências, o Brasil amadureceu suas reflexões e desenvolveu propostas de avaliação da educação superior, vivenciadas por programas de avaliação, tanto em cursos de graduação como de pós-graduação (SINAES, 2007).

Assim, surgiu a partir das reflexões da Comissão Especial de Avaliação (CEA), uma proposta de "Sistema Nacional de Avaliação da Educação Superior". Essa nova proposta que corresponde ao atual Sistema Nacional de Avaliação da Educação Superior (SINAES) tem como objetivo levar à sociedade o conhecimento acerca da qualidade de cada Instituição. Um sistema que articule de forma coerente concepções, objetivos, metodologias e práticas resguardadas às especificidades das IES - Instituições de Ensino Superior (SINAES, 2007, p. 88-89).

Um sistema de avaliação que combina regulação com avaliação, considerando as dimensões interna e externa, conjugando dados quantitativos com qualitativos, com enfoques de responsabilidade compartilhada do Estado e de Instituições (SCHEFFER, 2007).

\subsection{Espaço virtual}

Para a autora deste trabalho "Espaço Virtual é um local de compartilhamento de informações, experiências e lições aprendidas, podendo ser acessado por pessoas autorizadas, com direito de atualizações e inserções de conteúdo".

Dentre as opções para a viabilização do espaço virtual, uma delas é a criação de uma wiki, que segundo é Bottentuit Jr. e Coutinho (2008), a ideia central da tecnologia wiki é que qualquer texto original possa ser alterado, de modo a que novos conhecimentos sejam incorporados aos já existentes, ou seja, em wikis abertos qu'alquer pessoa pode editar uma página. Já em wikis com acesso restrito para edição, somente os utilizadores cadastrados ou com a permissão do administrador podem contribuir com novos conteúdos ou modificar os existentes.

A wiki permite que os membros de um determinado setor, departamento ou mesmo organização, insiram informações ou modifiquem os textos já publicados. Quando é postada uma nova informação na wiki, todos os membros podem contribuir inserindo complementos ao texto original, ou corrigindo o que foi publicado. Não há necessidade de pedir permissão ao autor porque todos estão sempre convidados a contribuir.

Junior e Coutinho (2008) ainda afirmam que a procura e construção do conhecimento são princípios impulsionadores da criação de uma wiki e, como resultado, torna-se possível a criação de um repositório coletivo de dados com informações que podem ser lidas e modificadas a todo instante por todos aqueles que se interessam ou dominam uma dada área do saber. Estes repositórios são importantes para a valorização dos 
indivíduos que participam na construção da wiki, bem como para a troca de conhecimentos entre todos os membros desse mesmo grupo.

\subsection{Núcleo de avaliação institucional da graduação}

O Núcleo de Avaliação Institucional da Graduação - NAIG está ligado à Pró Reitoria de Graduação da UNISC. destacar:

Dentre as principais atividades desenvolvidas pelo NAIG, pode-se

a)assessorar as coordenações dos cursos de graduação da IES nos processos de regulação, organizando e montando os processos dos cursos, com vistas ao cadastro no sistema EMEC (Sistema on-line, onde a IES informa ao MEC novos cursos ou atualizações de cursos já ofertados) para efeitos de Avaliações externas realizadas pelo Instituto Nacional de Estudos e Pesquisa INEP/MEC, com foco na regulação dos cursos;

b)coletar, sistematizar e cadastrar em sistema on-line específico os estudantes habilitados para o Exame Nacional de Desempenho dos Estudantes - ENADE, de acordo com as áreas avaliadas anualmente;

c)atualizar constantemente o Cadastro de Cursos no E-MEC.

Além de outras atividades, decorrentes de demandas que surgem para atender solicitações que auxiliam no processo de tomada de decisão da gestão superior.

\subsection{Trabalhos relacionados}

O objetivo de desenvolver a gestão do conhecimento é, basicamente, facilitar o acesso humano à informação e conhecimento para a tomada de decisão eficaz, além da resolução de problemas em situações de trabalho, na sua vida diária (KEBEDE, 2010).

Assmann, Frozza e Kipper (2012) apresentam um estudo cujo objetivo é mostrar a elaboração de um diagnóstico quanto à capacidade de criar, adquirir e transferir conhecimento no Setor de Informática de uma Instituição de Ensino Superior. E, a partir deste, definir um plano de melhoria na capacidade desta área de gerir o conhecimento.

Entre estas melhorias pode ser destacada a implantação de ferramenta de colaboração corporativa com o intuito de construção conjunta do conhecimento, de garantir o seu registro para que este não seja perdido, bem como facilitar o acesso aos demais colaboradores para que estes o reutilizem. A facilidade no acesso e registro de informações traz como resultado imediato o aumento na retenção do conhecimento, útil para os processos da organização. 
Laino et al. (2008) apresentam um trabalho cujo objetivo é analisar como uma grande instituição financeira brasileira pensa e implanta a Gestão do Conhecimento e até que ponto a ferramenta wiki contribui para esta. Foi utilizado pelos autores o método do Estudo de Caso através de análise documental e entrevistas realizadas na área de Tecnologia da Informação. O principal resultado do trabalho é que a contribuição da ferramenta para Gestão do Conhecimento é percebida de forma diferente por analistas e gestores, sendo que os primeiros são unânimes em afirmar que a ferramenta garante a realização de todo o ciclo do conhecimento, enquanto os últimos são unânimes em afirmar que não, embora possa contribuir.

Os trabalhos relacionados estudados utilizam a wiki como ferramenta colaborativa para o compartilhamento do conhecimento adquirido pelos membros das equipes envolvidas, permitindos aos mesmos postarem suas experiências e conhecerem diferentes visões sobre os assuntos abordados. Também pretende-se, nesta pesquisa, contribuir para avanços na implantação da gestão do conhecimento em diversas atividades.

\section{Procedimentos metodológicos}

Para realização do trabalho, foi necessária a definição de uma metodologia, envolvendo as seguintes etapas:

a)pesquisa bibliográfica sobre os assuntos relacionados à pesquisa desenvolvida : gestão do conhecimento; processo de avaliação institucional; ferramenta wiki como espaço virtual e trabalhos relacionados ao assunto.

b)aplicação de um questionário para realização do diagnóstico no NAIG, para a identificação das necessidades. Para esta etapa foi elaborado um questionário, com cinco (5) perguntas objetivas e seis (6) descritivas, visando levantar os dados do setor e, a partir disso, analisar quais as melhorias que podem ser implantadas em relação ao tema proposto.

c)análise do diagnóstico: para esta etapa foi utilizada a técnica de análise de conteúdo, que para Bardin (1977), é um conjunto de técnicas de análise das comunicações visando obter, por procedimentos sistemáticos e objetivos de descrição do conteúdo das mensagens, indicadores (quantitativos ou não) que permitam a inferência de conhecimentos relativos às condições de produção/recepção (variáveis inferidas) destas mensagens.

d)desenvolvimento da wiki como espaço virtual e sua implantação no NAIG. 


\section{Análise do diagnóstico}

Nos quadros de 1 a 7 a seguir, são apresentadas as respostas do questionário aplicado aos membros do NAIG, duas pessoas. No total, três pessoas trabalham neste setor.

\section{Quadro 1 - Processos do setor de trabalho}

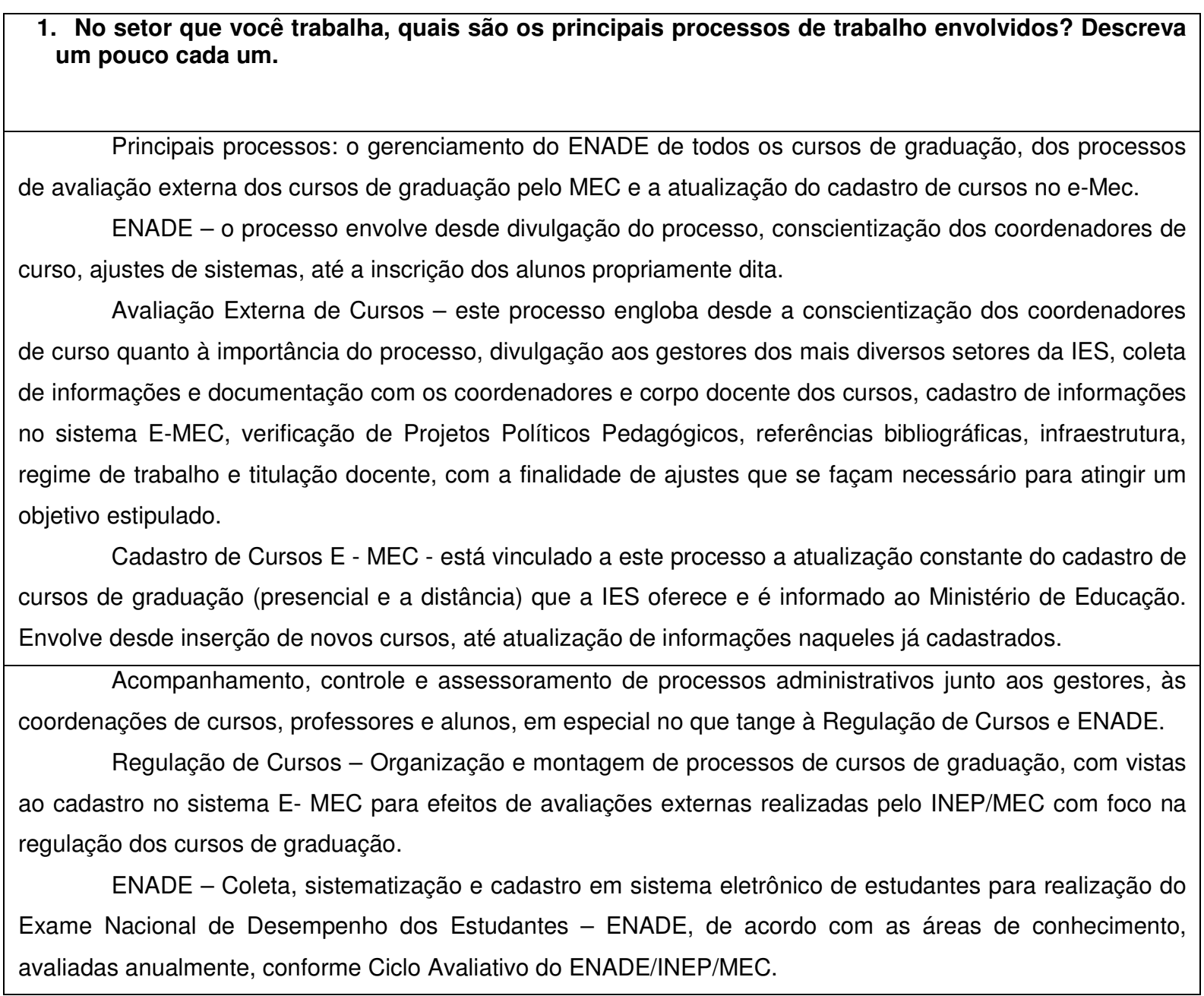

\section{Quadro 2 - Fontes de informações para os processos do setor}

\section{Quais são as fontes de informações que norteiam os processos desenvolvidos no setor? E de que forma estão disponibilizadas para acesso?}

ENADE - as fontes deste processo estão baseadas na legislação vigente, normalmente portarias e resoluções do MEC e a maioria das informações necessárias são acessadas no sistema acadêmico da IES (informatizado). Existem algumas informações que precisam ser garimpadas manualmente, pois ainda não foram informatizadas ou possuem problemas.

Avaliação Externa de Cursos - as fontes que servem de base para este processo também inclui a legislação vigente, normalmente emitida pelo Ministério de Educação (portarias, resoluções, decretos), bem como os Projetos Político Pedagógicos, Sistema de RH, Sistema da Biblioteca, Sistema Acadêmico (Catálogo Online), plataforma lattes CNPQ, bem como as coordenações de cursos envolvidos nos processos. 
Cadastro de Cursos E-MEC - essencialmente para este processo servem de fonte os Editais dos vestibulares da IES, bem como os Projetos Políticos Pedagógicos dos cursos.

- Políticas Públicas do Ministério da Educação para a Educação Superior do país.

- Políticas Institucionais estabelecidas no PDI, PPI e PAIUNISC da IES.

- Aparato legal do SINAES/CONAES/INEP/MEC, SESU/MEC, SERES/MEC, MEC, CNE, LDB n 9394/96.

- Referencial teórico e normatizações - Instrumentos de Avaliação do INEP/MEC.

São acessadas de forma impressa e digital, em sites e em sistemas próprios do MEC.

\section{Quadro 3 - Percepção sobre fontes disponíveis}

\section{Você considera as fontes de informação disponíveis claras e/ou compreensivas, refletindo a realidade?}

Como existem fontes distintas, algumas vezes pode ocorrer inconsistência de dados. Nesses casos é preciso realizar uma verificação um pouco mais apurada para ter certeza da informação. No sistema acadêmico da IES, não fica totalmente claro a procedência das informações e como dependemos de fontes baseadas na legislação, isto nos remete a interpretações diversas, dependendo, por vezes, do indivíduo que interpreta.

Sim, em princípio. Entretanto, considerando que o tema Avaliação contempla em sua concepção uma parcela de subjetividade, há situações em que a interpretação de normas e/ou critérios de avaliação despertam questionamentos e/ou compreensões que necessitam de esclarecimentos junto aos órgãos governamentais.

\section{Quadro 4 - Percepção sobre disponibilidade de informação}

\section{Você sente necessidade da disponibilidade de informações por meio de outras fontes?}

De certa forma sinto a necessidade de ter acesso a informações veiculadas em reuniões onde ocorrem as tomadas de decisões, que por sua vez desencadeiam os processos e/ou atividades pertinentes ao que compete o trabalho do nosso setor. Porém, como acredito que o indivíduo não tenha que viver alienado, não me limitaria apenas às informações pertinentes ao setor e sim ao contexto institucional como um todo. Como a universidade prega uma política democrática, acredito que poderia haver mais transparência e menos hierarquia, o que, por vezes, emperra os processos ou desqualifica o trabalho, tornando-o ineficiente.

Sim. Através de publicações sobre avaliação de cursos, relatos de experiências, fundamentos e concepções sobre Avaliação, atualizados e coerentes com as atuais políticas públicas para avaliação da Educação Superior.

\section{Quadro 5 - Sistema Computacional}

\section{Existe o uso de algum sistema computacional no setor? Se sim, qual (is)? Descreva-os de forma geral.}

Temos acesso ao Sistema Acadêmico, que, em princípio, engloba todas as informações referentes aos cursos de graduação. No que se refere à questão de serviços a IES possui um sistema de workflow, onde ficam registradas as demandas geradas pelos setores.

Sim. Catálogo Online; Sistema E-MEC; Sistema Acadêmico.

\section{Quadro 6 - Respostas às perguntas objetivas}

\begin{tabular}{|c|c|c|c|}
\hline Pergunta & $\begin{array}{c}\text { Número de } \\
\text { pessoas }\end{array}$ & $\begin{array}{c}\text { Sim ou Às } \\
\text { Vezes ou }\end{array}$ & Observação \\
\hline
\end{tabular}




\begin{tabular}{|c|c|c|c|}
\hline & & Não & \\
\hline $\begin{array}{l}\text { 6. Em situações complexas e quando } \\
\text { tenho dúvidas, procuro dialogar } \\
\text { com os meus colegas em primeiro } \\
\text { lugar para solucioná-las. }\end{array}$ & 2 pessoas & Sim & \\
\hline \multirow[t]{2}{*}{$\begin{array}{l}\text { 7. Ajusto-me facilmente às mudanças, } \\
\text { ao ambiente e às circunstâncias. }\end{array}$} & 1 pessoa & Sim & $\begin{array}{l}\text { Em relação ao ambiente físico, } \\
\text { minha adaptação é mais lenta. }\end{array}$ \\
\hline & 1 pessoa & Às vezes & \\
\hline \multirow[t]{2}{*}{$\begin{array}{l}\text { 8. Atualizo-me constantemente em } \\
\text { busca da melhoria contínua. }\end{array}$} & 1 pessoa & Sim & $\begin{array}{l}\text { Sinto necessidade permanente de } \\
\text { atualização e desafios na profissão. }\end{array}$ \\
\hline & 1 pessoa & Às vezes & \\
\hline \multirow[t]{2}{*}{$\begin{array}{l}\text { 9. Sou motivado para pesquisar novas } \\
\text { tecnologias, estudar e criar novos } \\
\text { conhecimentos, mesmo em horário de } \\
\text { trabalho. }\end{array}$} & 1 pessoa & Sim & $\begin{array}{l}\text { Tenho fragilidades no domínio e } \\
\text { utilização das tecnologias, } \\
\text { entretanto tenho muito interesse e } \\
\text { disciplina para continuar em } \\
\text { processo de educação continuada } \\
\text { e construção de novos } \\
\text { conhecimentos. }\end{array}$ \\
\hline & 1 pessoa & Não & \\
\hline \multirow{2}{*}{$\begin{array}{l}\text { 10. Tenho disponíveis informações } \\
\text { sobre atividades, novos conceitos ou } \\
\text { qualquer outra informação sobre o } \\
\text { setor como um todo. Mesmo que } \\
\text { estas informações não sejam } \\
\text { solicitadas, estão disponíveis e tenho } \\
\text { acesso a elas de forma rápida. }\end{array}$} & 1 pessoa & Sim & \\
\hline & 1 pessoa & Às vezes & \\
\hline
\end{tabular}

\section{Quadro 7 - Sugestões para compartilhar o conhecimento}

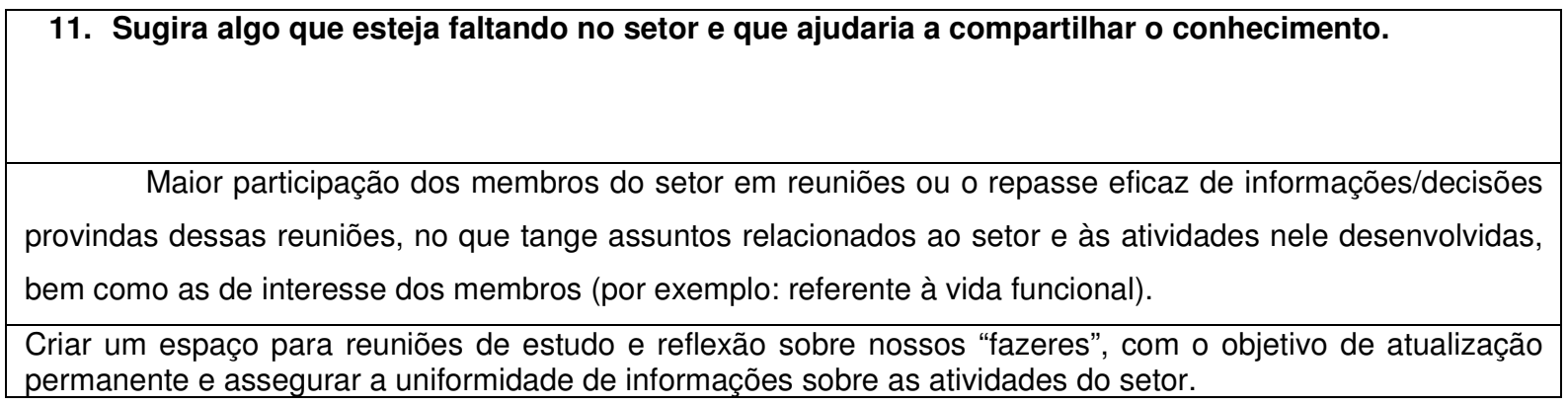

A partir do questionário respondido pelos membros do NAIG, foi possível observar a necessidade da criação de um espaço para estudos e reflexões sobre as atividades do setor. O objetivo é manter atualizada e assegurada a uniformidade das informações sobre as atividades desenvolvidas no setor, bem como, 0 repasse eficaz de informações/decisões decorrentes de reuniões.

Desta forma, optou-se pelo desenvolvimento de um espaço virtual, uma wiki, devido à facilidade de interação e eficiência, permitindo o compartilhamento do conhecimento e de informações. A ferramenta estará disponível e acessível a qualquer momento para todos os membros do setor envolvidos nas atividades de avaliação.

\section{Desenvolvimento da ferramenta colaborativa}


Esta seção apresenta o desenvolvimento e a implatação da wiki no Núcleo de Avaliação Institucional da Graduação - NAIG da UNISC.

\subsection{MediaWiki}

O MediaWiki é uma ferramenta open source para criação de sites colaborativos, desenvolvida em PHP e com banco de dados MySQL. Os sites que utilizam este sistema, como o Wikipédia, permitem a qualquer pessoa criar e alterar o conteúdo de suas páginas. O MediaWiki funciona como um gerenciador de conteúdo para sites colaborativos. Uma característica notável das ferramentas wiki é a facilidade de edição e a possibilidade de criação de textos de forma coletiva e livre (HOST NET, 2013).

Segundo Host Net (2013), a ferramenta apresenta muitas vantagens como:

a)coletividade: o que faz um site wiki ser tão diferente das outras páginas da internet é, certamente, o fato de o conteúdo poder ser editado pelos usuários que por ele navegam. Desse modo, é possível corrigir erros, complementar ideias e inserir novas informações. Assim, um artigo é atualizado graças à coletividade;

b)ligando e criando páginas: wikis são verdadeiras mídias hipertextuais, com estrutura de navegação não-linear. Cada página geralmente contém um grande número de ligações para outras páginas;

c)controle dos usuários: no MediaWiki é possível limitar o acesso de usuários para publicação de conteúdo.

\subsection{Layout da wiki}

Baseado nas necessidades levantadas a partir do diagnóstico realizado, foi elaborado um projeto de layout para a wiki. A Figura 1 ilustra a estrutura dos tópicos que integram a ferramenta.

A estrutura da wiki apresentada na Figura 1 engloba os principais processos e fonte de informações do setor, como Legislação, que apresenta diversas portarias, leis, entre outros documentos expedidos pelo Ministério da Educação, e que subisidiam as avaliações externas para os cursos da Educação Superior.

No tópico ENADE é possível disponibilizar informações, prazos, diretrizes pertinentes a um determinado grupo de cursos que realizarão a prova do Enade em determinado ano. Além disso, também podem ser disponibilizadas as listas com os alunos cadastrados junto ao Enade e que realização a prova.

Nas Avaliações Externas há informações sobre a Organização Didático-Pedagógica, Corpo Docente e Infraestrutura, pertinentes aos cursos avaliados em determinado ano. 


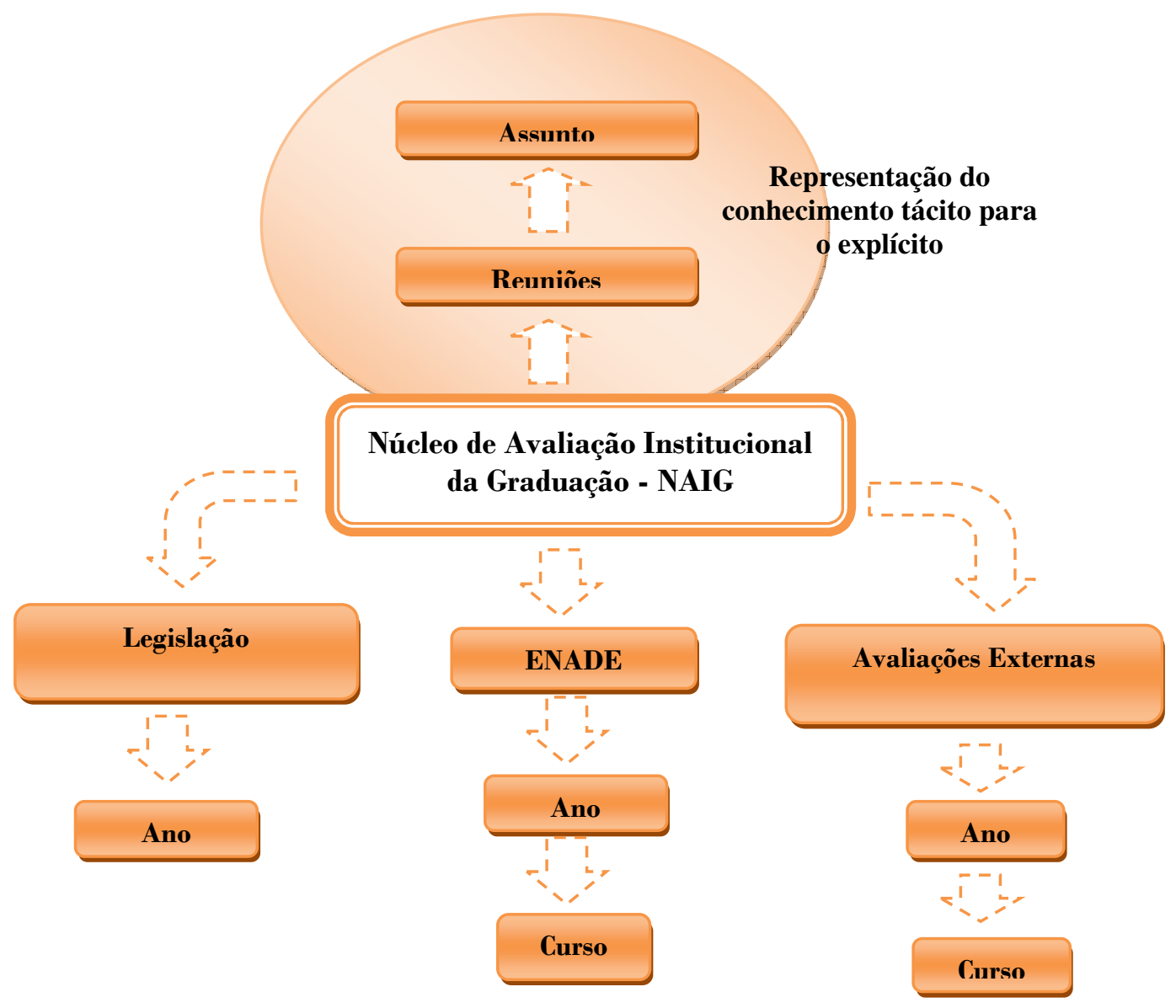

Figura 1 - Estrutura dos tópicos da wiki

Fonte: Dados da pesquisa.

Mas o foco deste trabalho é o tópico das reuniões, como foi indentificado no diagnóstico, e que representa a tranformação do conhecimento tácito em conhecimento explícito. Este tópico se refere a reuniões e/ou encontros que um ou dois funcionários do setor participaram e desejam compartilhar com os demais colegas do setor. Os subitens deste tópico são separados por assunto, o que facilita a busca, conforme ilustra a Figura 2. 


\section{Reunião Enade Área da Saúde}

Exame Nacional de Desempenho dos Estudantes

ENADE 2013

Dia $27 / 06 / 2013$

Horário: 10 h Sala: 2535

O ENADE tem como objetivo o acompanhamento do processo de aprendizagem e do desempenho acadêmico dos estudantes em relação aos conteúdos programáticos previstos nas Diretrizes Curriculares do respectivo curso.

--Ceres 10h26min de 8 de agosto de 2013 (BRT)

Fundamento Legal

- Lei 10.861 de 14 Abril de 2004 - SINAES.

- Portaria $n^{0} .40 / 2007$ - Republicada com alterações pela Portaria $n^{0}$. 23/12/2010.

- Portaria Normativa ${ }^{\circ} 6$ de 27 de março de 2013 - ENADE.

Mecanismos de Avaliação do SINAES

Com base na lei 10.861/2004 - SINAES

Avaliação Institucional Avaliação de Cursos (Externa, Interna) Exame Nacional de Desempenho dos Estudantes - ENADE

Figura 2 - Parte do conteúdo da reunião sobre Enade da área da saúde Fonte: Dados da pesquisa.

\subsection{Implantação da wiki}

A busca de ferramentas tecnológicas que auxiliem no processo de conversão do conhecimento tácito para explícito, de maneira que seja fácil sua socialização, não é uma tarefa trivial. Segundo Angeloni (2003) o processo de gerenciamento do conhecimento intra e inter organizacional é geralmente sutil e de difícil criação, captação, transmissão e armazenamento.

A implantação da wiki foi realizada no Núcleo de Avaliação Institucional da Graduação da UNISC - NAIG como apoio ao processo de Avaliação/Regulação dos Cursos de Graduação da Universidade de Santa Cruz do Sul (UNISC). 


\begin{tabular}{l|l|l|} 
Página especial & Pesquisa & Pesquisar \\
Entrar / criar conta &
\end{tabular}

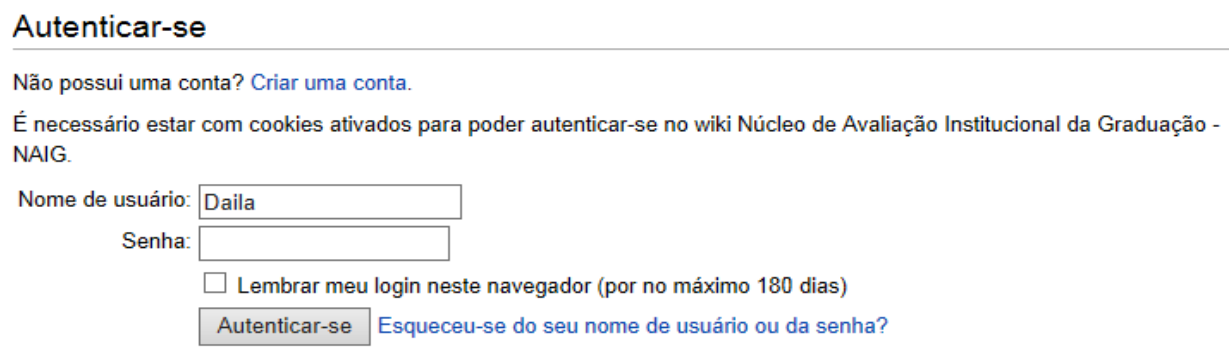

Figura 3 - Tela de autenticação da wiki

Fonte: Dados da pesquisa.

A Figura 3 apresentada ilustra a página de acesso à wiki, feito via web pelo link http://inf.unisc.br/naig/ com usuário e senha previamente cadastrados.

A Figura 4 mostra a página inicial da wiki, tendo o usuário já se autenticado previamente com seu login e senha.

$\mathrm{Na}$ página principal são apresentados todos os processos e informaçõess do setor, onde o usuário escolhe a informação que deseja acessar.

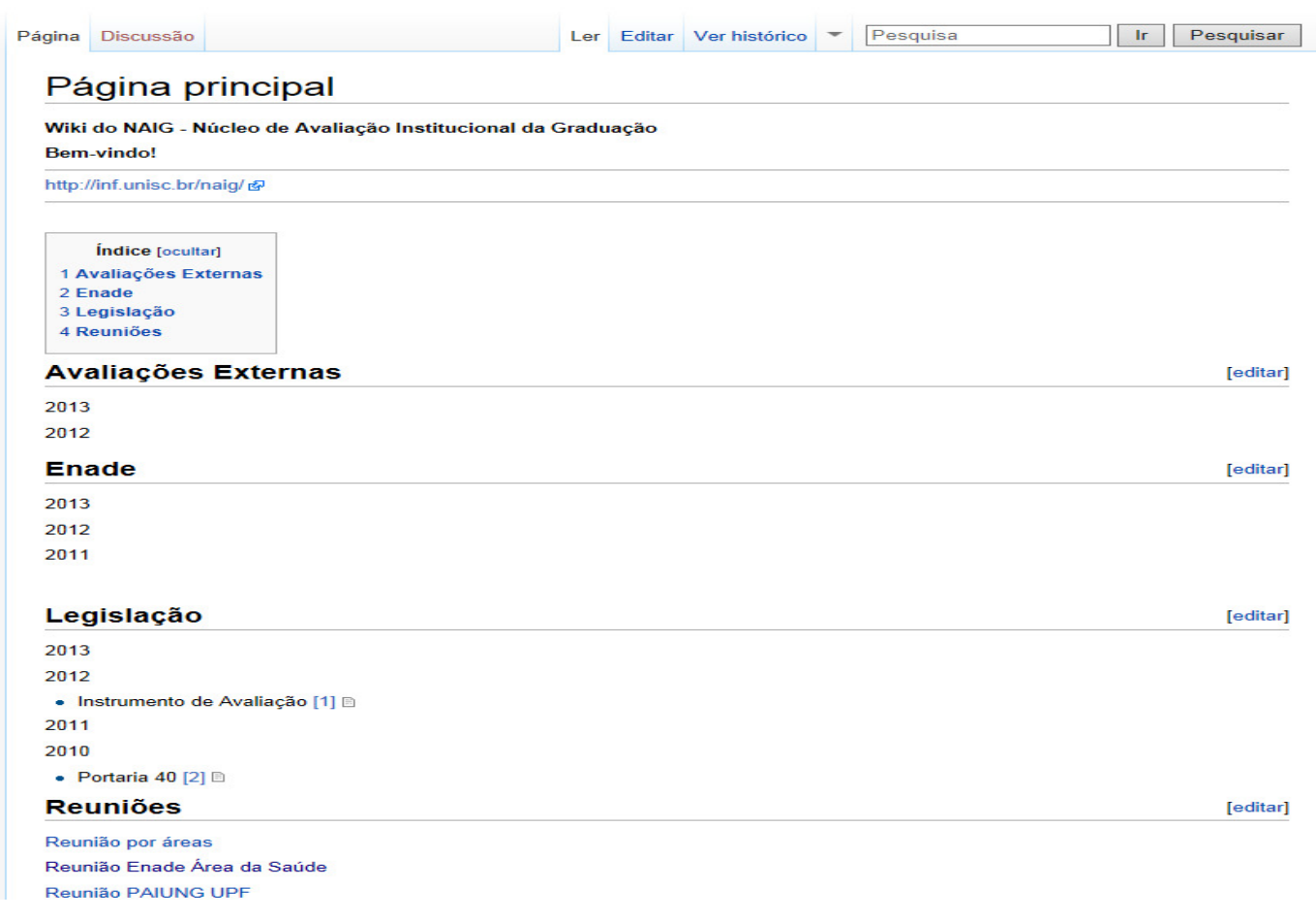

Figura 4 - Tela da página principal da wiki

Fonte: Dados da pesquisa. 
Figura 5.

A wiki permite o cadastro de vários usuários, conforme ilustra a

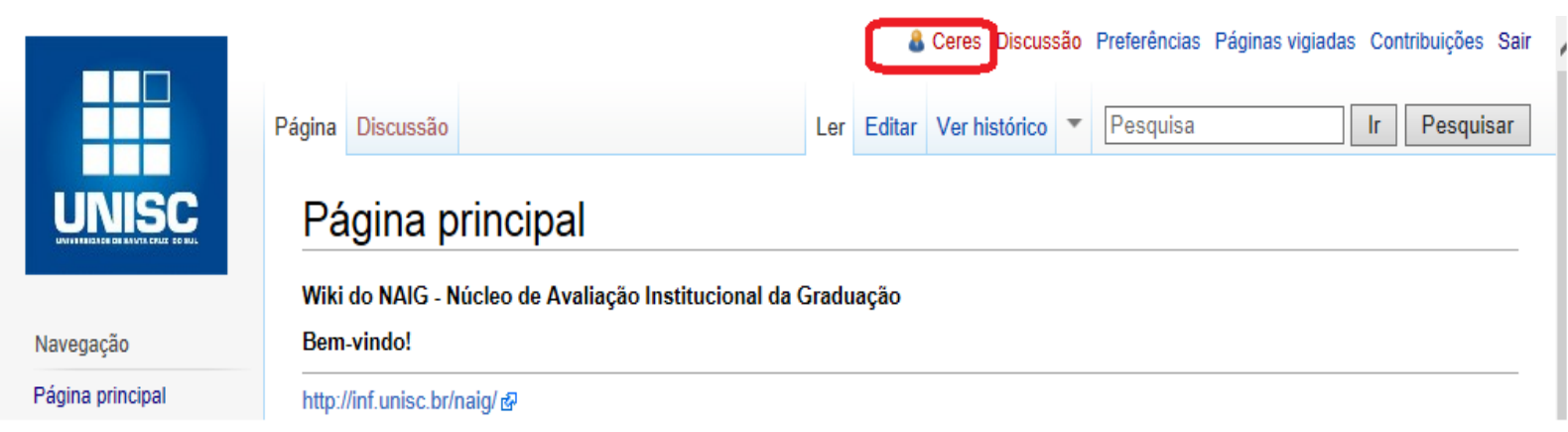

Figura 5 - Tela da página principal da wiki com usuário logado

Fonte: Dados da pesquisa.

E cada usuário cadastrado pode criar novos tópicos e também editar o conteúdo já disponibilizado (Figura 6), possibilitando acréscimos e alterações, ficando sua assinatura registrada no final do conteúdo (Figura 7).

\section{Editando Página principal}

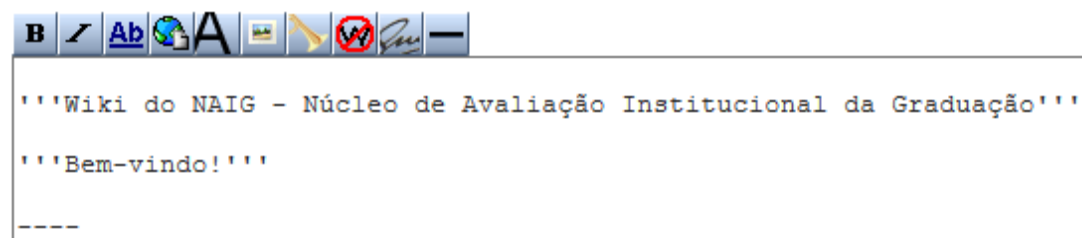

Figura 6 - Edição da página

Fonte: Própria autora

A próxima reunião ficou agendada para o dia 23 de agosto de 2013 no IPA - Assunto: Composição e Funcionamento da CPA No restante da manhã foram discutidas algumas tratativas para um Seminário que está sendo organizado pelo grupo, onde a sugestão de local ficou UNIVATES e reforçou-se a tentativa de trazer alguém da Coordenação Geral de Regulação para a palestra de abertura, que seria à noite. No dia sequinte haveria espaco para grupos de trabalho e exposição de pôster.

--Tanusa (discussão) 13h06min de 15 de agosto de 2013 (BRT)Tanusa Dumke.

Figura 7 - Registro da assinatura do usuário

Fonte: Dados da pesquisa.

Após a implantação da wiki, foi realizada a validação da ferramenta com os funcionários do setor. Estes realizaram diversos testes: inseriram conteúdos, alteraram informações, criaram novos tópicos, entre outros.

Após a validação, foi constatado, com base nas percepções dos funcionários, que a ferramenta virá a contribuir de forma significativa no compartilhamento de informações, na construção conjunta do 
conhecimento, agregando qualidade ao desempenho profissional e contribuindo como subsídio para reflexões da avaliação.

Além disso, a ferramenta é uma tecnologia simples e intuitiva que permite gerar documentação e dar suporte aos processos de forma fácil e completa.

\section{Conclusão}

Durante a elaboração deste artigo, foram estudados e apresentados os principais conceitos e informações sobre a gestão do conhecimento e o uso de espaço virtual (ferramenta colaborativa), abordados com o intuito de implantar a wiki no setor escolhido, a fim de disseminar e compartilhar o conhecimento tácito das pessoas envolvidas nos processos.

$\mathrm{Na}$ análise feita a partir do diagnóstico realizado no NAIG, foi possível identificar a necessidade de um espaço compartilhado de informações/experiências das pessoas envolvidas no processo de avaliação. Desta forma, foi desenvolvido e implantado um espaço virtual (ferramenta colaborativa).

Respondendo ao problema de pesquisa, citado na Introdução deste artigo, conclui-se que com a implantação deste espaço compartilhado de informações, há contribuições significativas para o setor, como: maior disseminação das informações entre os membros do setor; retenção de experiências e lições aprendidas; 0 fato de agregar qualidade ao desempenho profissional e, também como subsídio para reflexões sobre avaliação, com melhorias para as atividades desempenhadas pelo setor; construção coletiva do conhecimento referente às experiências dos membros do setor.

Também é relevante ressaltar em relação à ferramenta colaborativa (wiki), que a procura e a construção do conhecimento são princípios impulsionadores, tornando possível a troca de conhecimentos entre todos os membros e a criação do conhecimento coletivo que pode ser lido e modificado a todo instante por todos aqueles que se interessam ou dominam determinado assunto.

Durante a validação da wiki foram dadas sugestões que foram avaliadas e consideradas para trabalhos futuros:

a)implantação da wiki para os demais processos do setor, que já foram mencionados no layout da wiki, porém não foram o foco deste trabalho;

b)inserção de memoriais de cursos que passaram por avaliações externas, como forma de retenção do conhecimento aprendido e boas práticas;

c)inserção de manuais de determinados processos, como, por exemplo, o ENADE, de forma a socializar o conhecimento em processo específico.

Além disso, o desenvolvimento deste trabalho incentiva novas pesquisas sobre ferramentas colaborativas (wikis) e a contrução do 
conhecimento em qualquer tipo de organização. Desta forma, contribui para o processo de aprendizado, tanto na área acadêmica quanto em qualquer outra área de atuação profissional.

\section{Referências}

ACCORSI, F. L.; COSTA, J. P. A interação apoiada pela gestão do conhecimento e pelos serviços colaborativos. Revista TEXTOS de la CiberSociedad, n. 13. Temática Variada. 2008. Disponível em: <http://cibersociedad.net>. Acesso em: 25 nov. 2013.

ACCORSI, F. L. Conhecimento organizacional: uma análise conceitual que interliga valores, elementos e processos para a sua gestão. In: CISC, 9., Bento Gonçalves, 2011. Conference Knowledge-based Development: enterprises, cities and countries. Bento Gonçalves: [s.n.], 2011.

ANGELONI, M. T. Organizações do conhecimento: infra-estrutura, pessoas e tecnologia. São Paulo: Saraiva, 2003.

ARGOTE, L.; INGRAM, P. Knowledge transfer: a basis for competitive advantage in firms. Organizational Behavior and Human Decision Processes, v. 82, n. 1, p. 150-69, 2000 apud GUBBINS, C. et al. Evaluating a tacit knowledge sharing initiative: a case study. European Journal of Training and Development, v. 36, p. 827-847, 2012.

ASSMANN, C. L.; FROZZA, R.; KIPPER, L. M. Diagnóstico em gestão do conhecimento: estudo de caso na área de tecnologia da informação. In: CONGRESSO NACIONAL DE EXCELÊNCIA EM GESTÃO, 8., Rio de Janeiro, 2012. Anais... Rio de Janeiro: [s.n.], 2012.

BARDIN, L. Análise de conteúdo. Lisboa: Edições 70, 1977.

BOTTENTUIT JR., J. B.; COUTINHO, C. P. Wikis em educação: potencialidades e contextos de utilização. In: ENCONTRO SOBRE WEB 2.0, Braga, 2008. Actas... Braga: CIEd, 2008.

BEAL, A. Gestão estratégica da informação: como transformar a informação e a tecnologia da informação em fatores de crescimento e de alto desempenho nas organizações. São Paulo: Atlas, 2004.

DAVENPORT, T. H.; PRUSAK, L. Conhecimento empresarial: como as organizações gerenciam o seu capital intelectual. Rio de Janeiro: Campus, 1998 apud BEAL, A. Gestão estratégica da informação: como transformar a informação e a tecnologia da informação em fatores de crescimento e de alto desempenho nas organizações. São Paulo: Atlas, 2004.

DORFEY, D. E. Gestão do conhecimento aplicada à disponibilização de fluxos de trabalho com a técnica de storytelling. Santa Cruz do Sul: Universidade de Santa Cruz do Sul, 2009. Relatório de estágio para conclusão de Curso Secretariado Executivo.

GUBBINS, C. et al. Evaluating a tacit knowledge sharing initiative: a case study. European Journal of Training and Development, v. 36, p. 827-847, 2012. 
HOST NET. Hospedagem MediaWiki. Disponível em: < http://www.hostnet.com.br/app/wiki-mediawiki/>. Acesso em: 4 jun. 2013.

JAWORSKI, J. et al. Presença: propósito humano e o campo do futuro. São Paulo: Cultrix, 2007.

KEBEDE, G. Knowledge management: an information science perspective. International Journal of Information Management, Ethiopia, v. 30, n. 5, p. 416-424, 2010.

LAINO, C. P. et al. Uso de ferramenta Wiki para gestão do conhecimento: um estudo de caso em instituição financeira. In: ENCONTRO NACIONAL DE ENGENHARIA DE PRODUÇÃO (ENEGEP), 28., Rio de Janeiro, 2008. Anais... Rio de Janeiro: ENEGEP, 2008.

PFEIFER, M. Dicotomias conceituais da avaliação da educação superior. Avaliação: Revista da Avaliação da Educação Superior, v. 17, p. 351-364, 2012.

QUINN, J. et al. Intellect, Innovation and Growth. In:

HENRY, J.; MAYLE, D. (Eds.). Managing innovation and change.

London: Sagep, 2002. p. 5-22.

SCHEFFER, C. E. V. Avaliação de cursos na universidade de Santa Cruz do Sul e a qualificação da graduação: contribuições e influências do "olhar externo" da avaliação. Porto Alegre, 2007. Dissertação (Mestrado em Educação) - Pontifícia Universidade Católica do Rio Grande do Sul, Porto Alegre, 2007.

SINAES. Sistema Nacional de Avaliação da Educação Superior: da concepção à regulamentação. 4. ed. ampl. Brasília: Instituto Nacional de Estudos e Pesquisa Educacionais Anísio Teixeira, 2007.

STERNDALE-BENNETT. Defining knowledge management. British Journal

of Administrative Management, n. 26, p. 26-27, 2001 apud ACCORSI, F. L. Conhecimento organizacional: uma análise conceitual que interliga valores, elementos e processos para a sua gestão. In: CISC, 9., Bento Gonçalves, 2011. Conference Knowledge-based Development: enterprises, cities and countries. Bento Gonçalves: [s.n.], 2011.

VASCONCELLOS, C. dos S. Planejamento: projeto de ensinoaprendizagem e projeto político-pedagógico. 16. ed. São Paulo: Libertad, 2006. 